\title{
SHOUld GREEN GOVERNMENTS GIVE PRIORITY TO ENVIRONMENTAL POLICIES OVER GROWTH-ENHANCING POLICIES?
}

\author{
GEORGE ECONOMIDES \\ APOSTOLIS PHILIPPOPOULOS \\ CESIFO WORKING PAPER No. 1433 \\ CATEgory 5: FisCAl POLICY, MACROECONOMICS AND GROWTH \\ MARCH 2005
}

- from the CESifo website: Www.CESifo.de 


\title{
SHOUld GREEN GOVERNMENTS GIVE PRIORITY TO ENVIRONMENTAL POLICIES OVER GROWTH-ENHANCING POLICIES?
}

\begin{abstract}
This paper studies the properties of second-best optimal policy in a standard general equilibrium model of growth augmented with renewable natural resources. The government chooses its policy instruments (the income tax rate and the allocation of collected tax revenues between public investment and environmental policy) to solve a Ramsey-type policy problem. The main result is that, the more the citizens care about the environment, the more growth-enhancing policies the government finds it optimal to choose in the long run. This is because when citizens care about the environment, this requires tax revenues for environmental policy and can be only achieved by large tax bases and high growth. Thus, only growing economies can afford to care about the environment. This is the case even if pollution occurs as a by-product of output produced.
\end{abstract}

JEL Code: H23, Q2, O13.

Keywords: second-best policy, natural resources, economic growth.

\author{
George Economides \\ Department of International and \\ European Economic Studies \\ Athens University of Economics \& Business \\ 76 Patission Street \\ Athens 10434 \\ Greece \\ gecon@aueb.gr
}

\author{
Apostolis Philippopoulos \\ Department of International and \\ European Economic Studies \\ Athens University of Economics \& Business \\ 76 Patission Street \\ Athens 10434 \\ Greece \\ aphil@aueb.gr
}

We thank Panos Hatzipanayotou, Elissaios Papyrakis, Hyun Park and Vangelis Vassilatos for helpful discussions. All remaining errors are ours. 


\section{INTRODUCTION}

Is economic growth bad for the environment? Environmentalists believe that a slowdown in economic activity is needed in order to effectively protect the physical environment. Several economists, on the other hand, seem to believe that wealth and greenery are positively correlated. What is correct? Is there is a trade-off between economic growth and environmental quality? More importantly, should green policymakers give priority to environmental policies over growth enhancing policies?

This paper studies the properties of second-best optimal policy in a standard general equilibrium model of growth augmented with renewable natural resources. Natural resources are depleted by economic activity, but they can also be maintained by environmental policy. The government uses the collected tax revenues to finance infrastructure services and environmental policy. The former (i.e. infrastructure services) provides production externalities to firms and can be the engine of long-term growth as in Barro (1990). ${ }^{1}$ The latter (i.e. environmental policy) improves the quality of the environment, which enters the households' utility as a public good. ${ }^{2}$ Our work differs from the literature mainly because we study the optimal joint determination of the size of public sector, as well as the allocation of the collected tax revenues between public infrastructure and public cleanup policy in a unified dynamic general equilibrium framework.

We work as follows. First, we solve for a Competitive Decentralized Equilibrium (CDE), which is for any feasible policy. To the extent that private agents treat infrastructure and the environment as public goods, the CDE is inefficient and this justifies policy intervention. Second, we endogenize policy and solve for a General Equilibrium (GE) in which policy (summarized by the income tax rate and the allocation of tax revenues between public infrastructure and public environmental policy) is chosen optimally by a benevolent government that takes into account the CDE. In other words, we solve a Ramsey-type policy problem. Third, we study the properties of the resulting GE by distinguishing two cases: first, a non-growing economy where there is no long-term growth; second, a growing economy that is

\footnotetext{
${ }^{1}$ Well-known examples of such services are roads, airports, urban development, hospitals, police, etc.

${ }^{2}$ Policies that protect, conserve and generate (via innovation) the natural resources, as well as policies that provide the right environmental incentives, are costly activities that require public funds. Note that we will use the terms “environmental” and “cleanup” interchangeably.
} 
capable of long-term or endogenous growth. In both cases, there is no environmental damage so that we solve for what is known as sustainable balanced growth paths. We analyse the long run properties and the transitional dynamics in both the non-growing and growing economy.

Our main policy result is as follows. The more the citizens care about the environment, the more growth-enhancing policies the benevolent government finds it optimal to choose in the long run. Although this sounds paradoxical, it is consistent with a general lesson: in a dynamic framework, long-run tax bases are elastic and hence the provision of all types of public goods and services becomes fully endogenous. Thus, when citizens care about the environment, this requires tax revenues for public environmental policies and can be only achieved by large tax bases and high growth. Ramsey-type policymakers realize this and choose their policy instruments accordingly, in the sense that they give priority to growth. Notice that this happens even if environmental damage is modeled as a by-product of output produced.

Therefore, not only there is no tradeoff between economic growth and environmental protection in the long run, but also only growing economies can afford to improve environmental quality. This is consistent with the empirical evidence of e.g. Grossman and Krueger (1995) that there is no evidence that environmental quality deteriorates with economic growth (this is better known as "environmental Kuznets curve” in the sense that the deterioration of the environment is stopped and reversed as income rises). It is also consistent with cross-country reports that wealth certainly matters in the sense that per-head income is highly correlated with greenery (see e.g. The Economist, January $27^{\text {th }}$ 2001, pp. 86-89). Finally, it is consistent with other theoretical results (see e.g. Philippopoulos and Economides, 2003) that, concerning the provision of public goods, many policy lessons may change once one moves from static to dynamic frameworks.

How our work differs? The literature on growth, policy and the environment is rich. Since the 1970s, growth models have been studying the optimal use of natural resources (see e.g. the surveys by Kolstad and Krautkraemer, 1993; and Aghion and Howitt, 1998, chapter 5). More recently, the emphasis has shifted on policy issues with the literature reporting mixed results for the effect of environmental policy on economic growth (see, among many others, Ploeg and Withagen, 1991; Tahvonen and 
Kuuluvainen, 1993; John and Pecchenino, 1994; Ligthart and Ploeg, 1994; Bovenberg and Smulders, 1995, 1996; and Jones and Manuelli, 2001). Our work differs mainly because we study the joint determination of both tax policy and the allocation of collected tax revenues between public infrastructure and cleanup policy. ${ }^{3}$ Our work also differs from most of the environmental literature because here we study (Ramsey) second-best optimal policy in a dynamic general equilibrium model of growth. Jones and Manuelli (2001) use a model close to ours but they focus on the comparison of voting over effluent charges and over direct regulation of technology.

The rest of the paper is as follows. Section 2 presents the economy and solves for a Competitive Decentralized Equilibrium. Section 3 solves for second-best optimal policy and hence a General Equilibrium. A non-growing case is studied in Section 4, and a growing case is studied in Section 5. Section 6 concludes. Proofs are gathered in an Appendix.

\section{THE ECONOMY AND COMPETITIVE EQUILIBRIUM}

Consider a closed economy populated by private agents (a representative household and a representative firm) and a government. Households purchase goods, work and save in the form of capital. They get utility from private consumption and the stock of natural resources, where the latter is treated as a public good. Firms produce output by using private inputs (capital and labor) and public infrastructure. In doing so, they pollute the environment. The government imposes taxes on the polluting firm's output, ${ }^{4}$ and then uses the collected tax revenue to do two things: to finance public infrastructure that basically favors the firm, and to clean up the environment that basically favors the household. We build on Barro's (1990) well-known model so that our results are directly comparable to his at any stage of the solution.

The timing of events is as follows. First, the benevolent government chooses economic policy, namely the tax rate as well as the allocation of scarce tax revenues between public investment and cleanup policy. Second, private agents make their own decisions by taking as given prices, policy and natural resources. These decisions (plus cleanup policy) affect residually the motion of natural resources. We will solve

\footnotetext{
${ }^{3}$ Park and Philippopoulos (2004) also study the optimal allocation between public consumption and production services, although in a model without natural resources.

${ }^{4}$ Our main results do not change if taxes are imposed on households.
} 
the model by backward induction, so that we start from private agents' problems. We assume continuous time, infinite horizons and perfect foresight. We also assume a commitment technology on the part of the government so that the government chooses policy once-and-for-all by solving a typical Ramsey-type policy problem.

\subsection{Household's behavior}

The representative infinite-lived household maximizes intertemporal utility given by:

$$
\int_{0}^{\infty}[u(c, N)] e^{-\rho t} d t
$$

where $c$ is private consumption, $N$ is the stock of economy-wide natural resources and the parameter $\rho>0$ is the rate of time preference. The utility function $u($.$) is$ increasing and concave in its two arguments, and also satisfies the Inada conditions. For simplicity, we use an additively separable and logarithmic utility function:

$u(c, N)=\log c+v \log N$

where the parameter $v \geq 0$ is the weight given to environmental quality relative to private consumption.

Households can save in the form of capital, $a$. When they rent out $a$ to firms, they receive a rate of return, $r$. They also supply inelastically one unit of labor services so that they get labor income, $w .{ }^{5}$ Further, they receive dividends, $d$, from firms. Thus, the flow budget constraint of the representative household is:

$\dot{a}+c=r a+w+d$

where a dot over a variable denotes time derivative. The initial stock $a_{0}$ is given.

\footnotetext{
${ }^{5}$ We assume away endogenous labor supply to keep the model simple. We believe this is not important.
} 
The household acts competitively by taking prices, economic policy and natural resources as given. The control variables are the paths of $c$ and $a$, so that the first-order conditions are equation (2a) and the familiar Euler condition:

$\dot{c}=(r-\rho) c$

\subsection{Firm's behavior}

As in the model introduced by Barro (1990), we assume that public services provide production externalities to private firms and that technology takes a Cobb-Douglas form at the firm's level. Thus, the production function of the representative firm is:

$y=A k^{\alpha} l^{1-\alpha} G^{1-\alpha}$

where $y$ is output produced, $k$ is the input of physical capital, $l$ is labor input, $G$ is public production services, and $A>0$ and $0<\alpha<1$ are parameters.

The representative firm maximizes profits, $\pi$ :

$\pi=(1-\tau) y-r k-w l$

where $0<\tau<1$ is a proportional tax rate on firms' output.

The firm acts competitively by taking prices, economic policy and natural resources as given. This is a simple static problem. The control variables are $k$ and $l$, and the standard first-order conditions are:

$$
\begin{aligned}
& r=\alpha(1-\tau) \frac{y}{k} \\
& w=(1-\alpha)(1-\tau) \frac{y}{l}
\end{aligned}
$$

so that profits are zero in equilibrium.

\subsection{Motion of natural resources}

The stock of renewable natural resources, $N$, evolves over time according to: 
$\dot{N}=\delta N-P+\theta E$

where the parameter $\delta \geq 0$ is the rate of regeneration of natural resources, $P$ is environmental damage (see below), $E$ is public resources allocated to cleanup policy (see below) and the technology parameter $0 \leq \theta \leq 1$ measures the effectiveness of cleanup policy. The initial stock $N_{0}$ is given. In what follows, and without loss of generality, we set $\theta \equiv 1$. Thus, the idea in equation (6) is that natural resources can be renewed by regeneration and public policy.

We assume that $P$ is a by-product of final output produced, $y .{ }^{6}$ Specifically,

$P=s y$

that is, one unit of output generates $0 \leq s<1$ units of pollution. Thus, $s$ is a technology parameter that quantifies the detrimental effect of economic activity on the environment.

\subsection{Government budget constraint and the role of policy}

On the revenue side, the government taxes the polluting firm's output at a rate $0<\tau<1$. On the expenditure side, the government spends on infrastructure, $G$, and cleanup policy, E . Assuming a balanced budget, we have:

$G+E=\imath y$

Without any loss of generality, we re-write (8a) as:

$G=b \tau y$

$E=(1-b) \tau y$

where $0<b \leq 1$ is the share of tax revenues that goes to public infrastructure, while the rest $0 \leq(1-b)<1$ is the share that goes to cleanup policy. Inspection of (8a)-(8c)

\footnotetext{
${ }^{6}$ Our main results do not change if pollution is also a by-product of consumption. Alternatively, one can model natural resources as an input in private production.
} 
reveals that at each instant, economic policy can be fully summarized by the output tax rate, $\tau$, and the share of tax revenues that finances public infrastructure, $b$.

\subsection{Competitive decentralized equilibrium (for any feasible policy)}

We now solve for a Competitive Decentralized Equilibrium (CDE). In this equilibrium: (i) households maximize utility and firms maximize profits; (ii) all constraints are satisfied; (iii) all markets clear. ${ }^{7}$ This holds for any feasible economic policy, where the latter is summarized by the paths of the independent policy instruments, $0<\tau<1$ and $0<b \leq 1$.

Combining (1)-(8), it is straightforward to show that a CDE is given by:

$$
\begin{aligned}
& \dot{c}=\left[\alpha(1-\tau) A^{\frac{1}{\alpha}}(b \tau)^{\frac{1-\alpha}{\alpha}}-\rho\right] c \\
& \dot{k}=(1-\tau) A^{\frac{1}{\alpha}}(b \tau)^{\frac{1-\alpha}{\alpha}} k-c \\
& \dot{N}=\delta N-[s-(1-b) \tau] A^{\frac{1}{\alpha}}(b \tau)^{\frac{1-\alpha}{\alpha}} k
\end{aligned}
$$

Equations (9a)-(9c) give the motion of consumption ( $c$ ), capital $(k)$ and natural resources $(N)$ in a CDE as functions of the independent policy instruments ( $0<\tau<1$ and $0<b \leq 1)$. Specifically, we will analyze the problem in terms of the ratios $\frac{\dot{c}}{c}, \frac{c}{k}$ and $\frac{N}{k}$ that will be constant in the long run. ${ }^{8}$

Before we endogenize policy, it is helpful to distinguish three possible cases, all of which exclude environmental damage in the long run. First, the case in which $\frac{\dot{c}}{c}=\frac{\dot{k}}{k}=\frac{\dot{N}}{N}=\gamma \equiv 0$, where $\gamma$ denotes the balanced growth rate. This is the case of a non-growing economy in which the stock of natural resources also remains

\footnotetext{
${ }^{7}$ The market-clearing conditions in the labor, capital and dividend markets are respectively $l=1$, $k=a$ and $\pi=d$.

${ }^{8}$ The model is $A K$ at economy-wide level. Specifically, in (9a)-(9c), $y=A^{\frac{1}{\alpha}}(b \tau)^{\frac{1-\alpha}{\alpha}} k$. Notice that if $N=s \equiv 0$ and $b \equiv 1$, we get Barro’s (1990) model.
} 
unchanged. ${ }^{9}$ Second, the case in which $\frac{\dot{C}}{c}=\frac{\dot{k}}{k}=\frac{\dot{N}}{N}=\gamma>0$. This is the case of a growing economy in which all quantities (including renewable natural resources) can grow at the same positive rate, $\gamma>0$, in the long run. ${ }^{10}$ This can apply to living organisms like fish, forests, cattle and to some extent water and atmospheric systems, which have a natural capacity to assimilate and cleanse themselves. But, in addition to biological regeneration, these resources can also grow in size over time thanks to environmental policy and innovation. Innovation can help even fossil fuels (oil, gas, etc) and non-energy minerals (copper, bauxite, etc) not to run out in the long run: new sources are found, the efficiency of extraction goes up, existing supplies are used more economically, and new substitutes are invented (see e.g. The Economist, January $\left.22^{\text {nd }}, 2005\right) .{ }^{11}$ Third, the case in which consumption and capital can grow at the same positive rate, $\frac{\dot{c}}{c}=\frac{\dot{k}}{k}=\gamma>0$, while the stock of natural resources remains unchanged, $\frac{\dot{N}}{N} \equiv 0.12$

What are the effects of policy instruments, $0<b \leq 1$ and $0<\tau<1$, on the CDE? As shown in Appendix A, in all three possible cases defined above, the ratios $\frac{c}{k}$ and $\frac{N}{k}$ monotonically increase with $0<b \leq 1$. Thus, an increase in the share of tax revenues allocated to infrastructure vis-à-vis cleanup leads to better environmental quality relative to private capital, $\frac{N}{k}$. Intuitively, an increase in public investment, that stimulates economic growth, $\gamma$, and thus increases the tax base, can provide the extra tax revenue required to finance green policies. Thus, growth-enhancing policies are eventually good not only for growth itself but also for the environment. To put it

\footnotetext{
${ }^{9}$ In this case, (9b) gives $\frac{c}{k}$ and in turn (9c) gives $\frac{N}{k}$. We also need restrictions on the policy instruments so as $\gamma=0$ in (9a); see below for further details.

${ }^{10}$ In this case, (9a) gives $\gamma$, then (9b) gives $\frac{c}{k}$ and in turn (9c) gives $\frac{N}{k}$.

${ }^{11}$ For renewable and non-renewable natural resources, and their growth capacities in particular, see e.g. Perman et al. (2003).

${ }^{12}$ In this case, (9a) gives $\gamma$, then (9b) gives $\frac{c}{k}$ and in turn (9c) gives $\frac{N}{k}$ (the value of $\frac{N}{k}$ differs from that in case two before).
} 
bluntly, once we are in a dynamic world where tax bases are endogenous, environmentalists should give priority to economic growth. This is very different from static models. Regarding the ratio $\frac{N}{C}$, this increases with $0<b \leq 1$ in case (ii), while in cases (i) and (iii), the effect of $0<b \leq 1$ on $\frac{N}{C}$ is non-monotonic and cannot be derived analytically (see Appendix A for details). Finally, the effects of the tax rate, $0<\tau<1$, on the CDE are non-monotonic and in the case of $\frac{c}{k}$ and $\frac{N}{k}$ cannot be derived analytically (see Appendix A for details). Obviously, equation (9a) implies that the growth $(\gamma)$ effect of the tax rate has the usual inverted-U pattern, as in Barro (1990).

We sum up this section. Equations (9a)-(9c) give a unique Competitive Decentralized Equilibrium (CDE) for any feasible policy as summarized by $\tau$ and $b$. Note that private agents have failed to internalize externalities. In particular, they have not taken into account the positive external effects of public infrastructure and have also ignored the adverse external effect of their decisions on the economy's natural resources. Hence, the CDE is inefficient and this justifies policy intervention. We will therefore move on to endogenize policy, $\tau$ and $b$. By choosing $\tau$ and $b$, the government will attempt to control for externalities and also raise funds optimally to finance its activities (public infrastructure and cleanup policy). It is worth pointing out that both government activities are able to address externalities and hence are productive in the standard sense that they improve resource allocation.

\section{SECOND-BEST OPTIMAL POLICY AND GENERAL EQUILIBRIUM}

To endogenize economic policy, we assume that the government solves a Ramseytype policy problem. That is, the government chooses the paths of the income tax rate, $0<\tau<1$, and the allocation of tax revenues between the two types of policy intervention, $0<b \leq 1$, so as to maximize the household's welfare in (1a)-(1b) subject to the CDE given by (9a)-(9c).

\section{Solution}


The current-value Hamiltonian, $H$, of this second-best policy problem is: ${ }^{13}$

$$
\begin{array}{r}
H \equiv \log c+v \log N+\lambda_{c} c\left[\alpha(1-\tau) A^{\frac{1}{\alpha}}(b \tau)^{\frac{1-\alpha}{\alpha}}-\rho\right]+\lambda_{k}\left[(1-\tau) A^{\frac{1}{\alpha}}(b \tau)^{\frac{1-\alpha}{\alpha}} k-c\right] \\
+\lambda_{n}\left[\delta N-[s-(1-b) \tau] A^{\frac{1}{\alpha}}(b \tau)^{\frac{1-\alpha}{\alpha}} k\right]
\end{array}
$$

where $\lambda_{c}, \lambda_{k}$ and $\lambda_{n}$ are dynamic multipliers associated with equations (9a), (9b) and (9c) respectively.

The first-order conditions with respect to $\tau, b, c, \lambda_{c}, k, \lambda_{k}, N, \lambda_{n}$ are respectively:

$$
\begin{aligned}
& \alpha \lambda_{c} c+\lambda_{k} k=\lambda_{n} k\left[\frac{s(1-\alpha)-(1-b) \tau}{1-\alpha-\tau}\right] \\
& \alpha \lambda_{c} c+\lambda_{k} k=\lambda_{n} k\left[\frac{s(1-\alpha)-(1-\alpha-b) \tau}{(1-\alpha)(1-\tau)}\right] \\
& \dot{\lambda}_{c}=\rho \lambda_{c}-\frac{1}{c}-\lambda_{c}\left[\alpha(1-\tau) A^{\frac{1}{\alpha}}(b \tau)^{\frac{1-\alpha}{\alpha}}-\rho\right]+\lambda_{k} \\
& \dot{C}=\left[\alpha(1-\tau) A^{\frac{1}{\alpha}}(b \tau)^{\frac{1-\alpha}{\alpha}}-\rho\right] c \\
& \dot{\lambda}_{k}=\rho \lambda_{k}-\lambda_{k}(1-\tau) A^{\frac{1}{\alpha}}(b \tau)^{\frac{1-\alpha}{\alpha}}+\lambda_{n}[s-(1-b) \tau] A^{\frac{1}{\alpha}}(b \tau)^{\frac{1-\alpha}{\alpha}} \\
& \dot{k}^{\frac{1-\alpha}{2}}=(1-\tau) A^{\frac{1}{\alpha}}(b \tau)^{\frac{1-\alpha}{\alpha}} k-c \\
& \dot{\lambda}_{n}=\rho \lambda_{n}-\frac{v}{N}-\delta \lambda_{n} \\
& \dot{N}=\delta N-[s-(1-b) \tau] A^{\frac{1}{\alpha}}(b \tau)^{\frac{1-\alpha}{\alpha}} k
\end{aligned}
$$

These necessary conditions are completed with the addition of a transversality condition that guarantees utility is bounded. A sufficient condition for this to hold is:

\footnotetext{
${ }^{13}$ As said above, we assume a commitment technology on behalf of the government so that economic policy is chosen once-and-for-all. Thus, we do not study time inconsistency issues.
} 


$$
\left[\alpha(1-\tau) A^{\frac{1}{\alpha}}(b \tau)^{\frac{1-\alpha}{\alpha}}-\rho\right]+\delta<\rho
$$

which says that the growth rate of consumption, $\left[\alpha(1-\tau) A^{\frac{1}{\alpha}}(b \tau)^{\frac{1-\alpha}{\alpha}}-\rho\right]$, plus the rate of regeneration of natural resources, $\delta$, should be less than the rate of time preference, $\rho .^{14}$

Following usual practice, and since the model can allow for long-run growth, we transform variables to make them stationary. ${ }^{15}$ Specifically, after some experimentation, we define the auxiliary variables $z \equiv \frac{c}{k}, x \equiv \frac{k}{N}, \psi \equiv \lambda_{k} k, \phi \equiv \lambda_{n} N$ and $\Omega \equiv \lambda_{c} c$. Thus, $\psi, \phi$ and $\Omega$ measure respectively the social value of the quantities of physical capital, natural resources and consumption, while $z$ and $x$ are the key ratios studied in the CDE above. Then, Appendix B shows that the dynamics of (11a)-(11h) are equivalent to the dynamics of (12a)-(12g) below:

$$
\begin{aligned}
& \dot{z}=\left[z-\rho-(1-\alpha)(1-\tau) A^{\frac{1}{\alpha}}(b \tau)^{\frac{1-\alpha}{\alpha}}\right] z \\
& \dot{\psi}=\left[-z+\rho+[s-(1-b) \tau] A^{\frac{1}{\alpha}}(b \tau)^{\frac{1-\alpha}{\alpha}} \frac{\phi x}{\psi}\right] \psi \\
& \dot{\phi}=\left[\rho-\frac{v}{\phi}-[s-(1-b) \tau] A^{\frac{1}{\alpha}}(b \tau)^{\frac{1-\alpha}{\alpha}} x\right] \phi \\
& \dot{x}=\left[(1-\tau) A^{\frac{1}{\alpha}}(b \tau)^{\frac{1-\alpha}{\alpha}}-z-\delta+[s-(1-b) \tau] A^{\frac{1}{\alpha}}(b \tau)^{\frac{1-\alpha}{\alpha}} x\right] X \\
& \dot{\Omega}=\left[\rho-\frac{1}{\Omega}+\frac{\psi z}{\Omega}\right] \Omega \\
& \tau b=(1-\alpha)(1-s) \\
& \alpha \Omega+\psi=\phi x
\end{aligned}
$$

\footnotetext{
${ }^{14}$ If $\lambda_{c} \geq 0, \lambda_{k} \geq 0, \lambda_{n} \geq 0$, and since the objective function and the constraints in (10) are quasiconcave in $\tau, b, c, k$ and $N$, the necessary conditions are also sufficient for optimality in a commitment equilibrium. See e.g. Kamien and Schwartz (1991). Things are different without commitment.

${ }^{15}$ See e.g. Mulligan and Sala-i-Martin (1993).
} 
where (12a)-(12g) constitute a seven-equation system in the time-paths of $z, \psi, \phi, x, \Omega, b, \tau$. Since (12f) and (12g) are atemporal, the dynamics of $b$ and $\tau$ will follow from the dynamics of $z, \psi, \phi, x$ and $\Omega$.

Therefore, equations (12a)-(12g) summarize a general equilibrium with second-best optimal policy. In what follows, we will study two cases of this economy. First, a non-growing economy. This is defined to be a case in which the quantities of consumption, capital and natural resources $(c, k$ and $N)$ do not change in the long run. Thus, among other long-run conditions shown below, $\dot{c}=\dot{k}=\dot{N}=\gamma \equiv 0$. Second, a growing economy. This is defined to be a case in which $c, k$ and $N$ grow at the same positive constant rate in the long run. Thus, among other long-run conditions shown below, $\dot{C}=\dot{k}=\dot{N}=\gamma>0$, where $\gamma$ is the endogenous balanced growth rate. Notice that in both cases we solve for a sustainable balanced growth path, in the sense that there is no environmental damage in the long run. Also notice that now we cannot solve for a third case in which $c$ and $k$ grow, but $N$ does not grow. ${ }^{16}$ In other words, the general equilibrium (where policy is optimally chosen) is more restrictive than the competitive decentralized equilibrium (which was for any feasible policy). Recall that the latter allowed for this combined case too (see subsection 2.5 above). By contrast, now where policy is optimally chosen, $c, k$ and $N$ have to grow at the same rate (zero or positive). Intuitively, since pollution and cleanup are proportional to economic activity (see equations (6), (7) and (8c) above), the policy-maker finds it optimal to choose his policy so as all quantities grow at the same rate. This is the efficient thing to do.

In what follows, we will study the long run behaviour and the transitional dynamics of the two cases defined above. We start with the non-growing case, which is simpler algebraically.

\section{CASE A: NON-GROWING ECONOMY}

\footnotetext{
${ }^{16}$ Since $z \equiv \frac{c}{k}$ and $x \equiv \frac{k}{N}$, the long-run conditions $\dot{z} \equiv 0$ and $\dot{X} \equiv 0$ imply that $c, k$ and $N$ have to grow at the same rate, i.e. $\frac{\dot{c}}{c}=\frac{\dot{k}}{k}=\frac{\dot{N}}{N}$.
} 
This section studies the case in which the economy does not grow in the long run. Thus, we set $\frac{\dot{z}}{z}=\frac{\dot{\psi}}{\psi}=\frac{\dot{\phi}}{\phi}=\frac{\dot{x}}{x}=\frac{\dot{\Omega}}{\Omega} \equiv 0$ in (12a)-(12g), and also $\frac{\dot{C}}{c} \equiv 0$ in (11d). We will study the properties of this economy both in the long run and along the transition path.

\subsection{Long-run solution}

Let denote the long-run values of $(z, \psi, \phi, x, \Omega, b, \tau)$ as $(\tilde{z}, \tilde{\psi}, \tilde{\phi}, \tilde{x}, \tilde{\Omega}, \tilde{b}, \tilde{\tau})$. Then, equations (12a), (12b), (12c), (12d), (12e) and (12f), jointly with (11d), give: ${ }^{17}$

$$
\begin{aligned}
& \tilde{z}=(1-\tilde{\tau}) A^{\frac{1}{\alpha}(\tilde{b} \tilde{\tau})^{1-\alpha}} \\
& \tilde{\psi}=\frac{v \delta}{(\rho-\delta)\left[(1-\tilde{\tau}) A^{\frac{1}{\alpha}}(\tilde{b} \tilde{\tau})^{\frac{1-\alpha}{\alpha}}-\rho\right]} \\
& \tilde{\phi}=\frac{v}{\rho-\delta} \\
& \tilde{x}=\frac{[s}{[s-(1-\tilde{b}) \tilde{\tau}] A^{\frac{1}{\alpha}}(\tilde{b} \tilde{\tau})^{\frac{1-\alpha}{\alpha}}} \\
& \tilde{\Omega}=\frac{1-\tilde{\psi} \tilde{z}}{\rho} \\
& \tilde{b}=\frac{(1-\alpha)(1-s)}{\tilde{\tau}} \\
& \tilde{\tau}=1-\frac{\rho}{\alpha A^{\frac{1}{\alpha}}[(1-\alpha)(1-s)]^{1-\alpha}}
\end{aligned}
$$

Equations (13a)-(13g) imply a unique and well-defined non-growing solution. In particular, we have:

PROPOSITION 1: If the parameter values satisfy the conditions:

\footnotetext{
${ }^{17}$ See below why we do not make use of (12g) at this stage of the solution.
} 
$\rho>\delta$

$\alpha^{2}(1-s) A^{\frac{1}{\alpha}}((1-\alpha)(1-s))^{\frac{1-\alpha}{\alpha}}<\rho<\alpha(s+\alpha(1-s)) A^{\frac{1}{\alpha}}((1-\alpha)(1-s))^{\frac{1-\alpha}{\alpha}}$

$(\rho-\delta)\left[\rho-\alpha^{2}(1-s) A^{\frac{1}{\alpha}}((1-\alpha)(1-s))^{\frac{1-\alpha}{\alpha}}\right]=v \delta \rho$

there exists a unique second-best optimal policy (summarized by $0<\tilde{\tau}<1$ and $0<\tilde{b} \leq 1$ ), which in turn supports a unique sustainable long-run equilibrium in which consumption, capital and renewable natural resources remain constant over time. This equilibrium is given by equations (13a)-(13g).

Proof: See Appendix C.

Conditions (14a)-(14b) are necessary and sufficient for a solution in (13a)(13g) to exist and be well defined. A solution is well defined when $\tilde{z}, \tilde{\psi}, \tilde{\phi}, \tilde{x}, \tilde{\Omega}>0$, $0<\tilde{b}<1$ and $0<\tilde{\tau}<1$. Condition (14c), on the other hand, is required for (12g) to hold. This is because, in the case of a non-growing economy, the long run tax rate is determined residually by setting (11d) equal to zero, so that an extra condition on the parameter values is needed for the first-order condition for the tax rate, (12g), also to hold; and this extra condition is provided by (14d). ${ }^{18}$

To confirm the possibility of the above analytical results, we also provide a numerical solution. ${ }^{19}$ Taking into account the conditions in Proposition 1, we set the following benchmark parameter values: $\alpha=0.35$ (where $0<\alpha<1$ is the productivity of private capital in the production function), $A=1$ (where $A>0$ is aggregate factor productivity in the production function), $\delta=0.015$ (where $\delta>0$ is the rate of regeneration of natural resources), $\rho=0.02$ (where $\rho>0$ is the rate of time preference) and $s=0.5$ (where $0<s<1$ is a technology parameter that quantifies the pollution effects of production activity). ${ }^{20}$ Then, conditions (14a)-(14b), as well as the transversality condition (11i), are all satisfied. Also, equation (14c) implies a value of

\footnotetext{
${ }^{18}$ One could ignore $(12 \mathrm{~g})$ in the long run. However, since it holds along the transition path, we prefer to respect it all the time including the long run.

${ }^{19}$ We use Maple 5.1 for numerical solutions.

${ }^{20}$ Most of these parameters are close to typical values used in the RBC literature or the environmental literature. The value of $0<s<1$ is set at 0.5 , which is a rather neutral value.
} 
$v$ equal to 0.206 . Note that we choose to solve (14c) for $v$, and not for any other parameter value, for two reasons: first, algebraic simplicity; ${ }^{21}$ second, and more importantly, economic intuition (for details, see below after we complete the study of a growing economy). Finally, using all these parameter values, equations (13a)-(13g) give a well-defined solution as reported in Table 1 (for comparative statics, see below).

\begin{tabular}{|c|c|c|c|c|c|c|}
\hline \multicolumn{7}{|c|}{ Table 1: Non-growing economy } \\
\hline$\tilde{\tau}$ & $\tilde{b}$ & $\tilde{z}$ & $\tilde{\psi}$ & $\tilde{\phi}$ & $\tilde{x}$ & $\tilde{\Omega}$ \\
\hline 0.54 & 0.60 & 0.057 & 16.7 & 41.3 & 0.42 & 2.29 \\
\hline
\end{tabular}

Notes: $\alpha=0.35, A=1, \delta=0.015, \rho=0.02, s=0.5, v=0.206$

\subsection{Transitional dynamics}

We now check whether the above long-run equilibrium is dynamically stable. We focus on local stability around the long run. Since equations (12f) and (12g) are atemporal, linearizing (12a)-(12e) around (13a)-(13g) implies that the local dynamics are approximated by the linear system:

$\left[\begin{array}{c}\dot{z} \\ \dot{\psi} \\ \dot{\phi} \\ \dot{x} \\ \dot{\Omega}\end{array}\right]=\left[\begin{array}{lllll}J_{z z} & J_{\psi z} & J_{\phi z} & J_{x z} & J_{\Omega z} \\ J_{z \psi} & J_{\psi \psi} & J_{\phi \psi} & J_{x \psi} & J_{\Omega \psi} \\ J_{z \phi} & J_{\psi \phi} & J_{\phi \phi} & J_{x \phi} & J_{\Omega \phi} \\ J_{z x} & J_{\psi x} & J_{\phi x} & J_{x x} & J_{\Omega x} \\ J_{z \Omega} & J_{\psi \Omega} & J_{\phi \Omega} & J_{x \Omega} & J_{\Omega \Omega}\end{array}\right]\left[\begin{array}{c}z \\ \psi \\ \phi \\ x \\ \Omega\end{array}\right]$

where the elements of the Jacobian evaluated at the long run are shown in Appendix D.

The determinant of the Jacobian matrix in (15), denoted by $\operatorname{det}(J)$, is $\operatorname{det}(J)=\tilde{Z}(\rho-\tilde{Z})(\rho-\delta) \delta \rho$, which is negative. ${ }^{22}$ Hence, with five eigenvalues, there are three possibilities: either all five eigenvalues are negative, or there are three negative and two positive eigenvalues, or there is one negative and four positive eigenvalues. Since four variables $(z, \psi, \phi, \Omega)$ are forward-looking or jump, and one variable $(x)$ is

\footnotetext{
${ }^{21}$ The value of $v$ does not enter equations (12f) and (12g).

${ }^{22}$ This is because $\rho-\tilde{z}<0$. Notice that $\alpha \tilde{z}-\rho$ is the economy's growth rate which equals 0 .
} 
backward-looking or predetermined, the last possibility (namely, one negative and four positive) would imply local determinacy (i.e. saddle-path stability), while the first two possibilities (namely, five negative, or three negative and two positive) would imply local indeterminacy (i.e. multiple trajectories, each of which is consistent with the same initial condition and with convergence to the same steady state). ${ }^{23}$ By examining the characteristic equation of the Jacobian matrix, it is straightforward to show in Appendix E that one root is negative and four roots are positive. Thus:

PROPOSITION 2: Under the conditions in Proposition 1, the long-run general equilibrium of a non-growing economy is saddle-path stable.

Proof: See Appendix E.

\section{CASE B: GROWING ECONOMY}

This section studies the case in which the same economy is capable of long-term, or endogenous, growth. Thus, now we set $\frac{\dot{Z}}{z}=\frac{\dot{\psi}}{\psi}=\frac{\dot{\phi}}{\phi}=\frac{\dot{x}}{x}=\frac{\dot{\Omega}}{\Omega} \equiv 0$ in (12a)-(12g). We will again study the properties of this economy both in the long run and along the transition path.

\subsection{Long-run solution}

Let denote the new long-run values of $(z, \psi, \phi, x, \Omega, b, \tau)$ as $(\tilde{z}, \tilde{\psi}, \tilde{\phi}, \tilde{x}, \tilde{\Omega}, \tilde{b}, \tilde{\tau})$. Then, when $\frac{\dot{\mathrm{Z}}}{\mathrm{z}}=\frac{\dot{\psi}}{\psi}=\frac{\dot{\phi}}{\phi}=\frac{\dot{x}}{x}=\frac{\dot{\Omega}}{\Omega} \equiv 0$, equations (12a)-(12g) give:

\footnotetext{
${ }^{23}$ For a review of indeterminacy in macroeconomics, see Benhabib and Farmer (1999). For a related
} 


$$
\begin{aligned}
& \tilde{z}=(1-\alpha)(1-\tilde{\tau}) A^{\frac{1}{\alpha}}((1-\alpha)(1-s))^{\frac{1-\alpha}{\alpha}}+\rho \\
& \tilde{\psi}=\frac{\left[\rho+\delta-\alpha(1-\tilde{\tau}) A^{\frac{1}{\alpha}}((1-\alpha)(1-s))^{\frac{1-\alpha}{\alpha}}\right] \tilde{\phi}}{(1-\alpha)(1-\tilde{\tau}) A^{\frac{1}{\alpha}}((1-\alpha)(1-s))^{\frac{1-\alpha}{\alpha}}} \\
& \tilde{\phi}=\frac{v}{\alpha(1-\tilde{\tau}) A^{\frac{1}{\alpha}}((1-\alpha)(1-s))^{\frac{1-\alpha}{\alpha}}-\delta} \\
& \tilde{x}=\frac{\rho+\delta-\alpha(1-\tilde{\tau}) A^{\frac{1}{\alpha}}(\tilde{b} \tilde{\tau})^{\frac{1-\alpha}{\alpha}}}{[s-(1-\tilde{b}) \tilde{\tau}] A^{\frac{1}{\alpha}}(\tilde{b} \tilde{\tau})^{\frac{1-\alpha}{\alpha}}} \\
& \tilde{\Omega}=\frac{1-\tilde{\psi} \tilde{z}}{\rho} \\
& \tilde{b}=\frac{(1-\alpha)(1-s)}{\tilde{\tau}}
\end{aligned}
$$

while $\tilde{\tau}$ is a solution to:

$$
\begin{aligned}
& (1-\tilde{\tau})\left(\alpha(1-\tilde{\tau}) A^{\frac{1}{\alpha}}((1-\alpha)(1-s))^{1-\alpha} \alpha\right)[1-\alpha-\tilde{\tau}+\alpha s] A^{\frac{1}{\alpha}}((1-\alpha)(1-s))^{\frac{1-\alpha}{\alpha}}= \\
& \quad\left\{\rho+\delta-\alpha(1-\tilde{\tau}) A^{\frac{1}{\alpha}}((1-\alpha)(1-s)) \frac{1-\alpha}{\alpha}\right]\left[\left((1-\tilde{\tau}) A^{\frac{1}{\alpha}}((1-\alpha)(1-s)) \frac{1-\alpha}{\alpha}[1-\alpha-\tau+\alpha s]+\alpha(1-s)\right)\right]
\end{aligned}
$$

The key equation is (16g) which is an equation in $\tilde{\tau}$ only. Once one solves (16g) for $\tilde{\tau}$, equations (16a)-(16f) can give unique solutions for $\tilde{z}, \tilde{\psi}, \tilde{\phi}, \tilde{x}, \tilde{\Omega}$ and $\tilde{b}$ respectively. In contrast with the non-growing case above, equation (16g) is a thirdorder polynomial which cannot be solved analytically for $\tilde{\tau}$; nor it is possible to show uniqueness of $\tilde{\tau}$. Nevertheless, we manage to establish conditions that are sufficient for existence of a well-defined solution, and in turn provide a numerical solution to confirm the possibility of such a solution and also study its comparative static properties. In particular, we establish:

public finance general equilibrium paper, see Park and Philippopoulos (2004). 
PROPOSITION 3: If the parameter values satisfy the conditions:

$$
\begin{aligned}
& 0<\alpha(1-\tilde{\tau}) A^{\frac{1}{\alpha}}((1-\alpha)(1-s))^{\frac{1-\alpha}{\alpha}}-\rho<\rho-\delta \\
& \delta<\rho<2 \delta \\
& (1-\alpha)(1-\tilde{\tau}) A^{\frac{1}{\alpha}}((1-\alpha)(1-s))^{\frac{1-\alpha}{\alpha}}\left(\alpha A^{\frac{1}{\alpha}}((1-\alpha)(1-s))^{\frac{1-\alpha}{\alpha}}-\delta\right)- \\
& \qquad\left(\rho+\delta-\alpha(1-\tilde{\tau}) A^{\frac{1}{\alpha}}((1-\alpha)(1-s))^{\frac{1-\alpha}{\alpha}}\right)\left((1-\alpha)(1-\tilde{\tau}) A^{\frac{1}{\alpha}}((1-\alpha)(1-s))^{\frac{1-\alpha}{\alpha}}+\rho\right)>0 \\
& (1-\alpha+\alpha s) A^{\frac{1}{\alpha}}((1-\alpha)(1-s))^{\frac{1-\alpha}{\alpha}}\left(\alpha A^{\frac{1}{\alpha}}((1-\alpha)(1-s))^{\frac{1-\alpha}{\alpha}}-\delta\right)- \\
& v\left(\rho+\delta-\alpha A^{\frac{1}{\alpha}}((1-\alpha)(1-s))^{\frac{1-\alpha}{\alpha}}\right)\left((1-\alpha+\alpha s) A^{\frac{1}{\alpha}}((1-\alpha)(1-s))^{\frac{1-\alpha}{\alpha}}+\rho(1-s)\right)>0
\end{aligned}
$$

there exists at least one second-best optimal policy (summarized by $0<1-\alpha-s(1-\alpha)<\tilde{\tau}<1-\alpha+\alpha s<1$ and $\left.1-\frac{s}{1-\alpha+\alpha s}<\tilde{b}<1\right)$, which in turn supports a sustainable long-run equilibrium in which consumption, capital and renewable natural resources grow at the same positive rate. This equilibrium is given by equations (16a)-(16g).

Proof: See Appendix F.

As shown in Appendix F, condition (17a) is sufficient for the growth rate to be positive, for the transversality condition in (11i) to hold, and for $\tilde{\psi}>0$. Condition (17b) is sufficient for $\tilde{\phi}>0$. Condition (17c) is sufficient for $\tilde{\Omega}>0$. Condition (17d) is sufficient for existence of equilibrium. ${ }^{24}$

We now solve (16a)-(16g) numerically. To do so, we use the same parameter values we used in the non-growing case above (namely, we set $\alpha=0.35, A=1$, $\delta=0.015, \rho=0.02$ and $s=0.5)$. We also set $0.206 \leq v \leq 0.33$, where recall that a

\footnotetext{
${ }^{24}$ Thus, as in the non-growing case, existence of a well-defined solution requires some extra parameter restrictions. It is hard to tell which case (the non-growing or the growing one) is more restrictive.
} 
well-defined solution in the non-growing case required $v=0.206 .^{25}$ Table 2 reports the solution for changing values of $v$, in the region $0.206 \leq v \leq 0.33 .{ }^{26}$ In the last two columns of this table, we also report results for the consumption-to-nature ratio, $\frac{\tilde{c}}{\tilde{N}}=\tilde{z} \tilde{x}$, and the balanced growth rate, $\gamma$, which is the common rate at which $c, k$ and $N$ grow (this is derived from (11d) above).

\begin{tabular}{|c|c|c|c|c|c|c|c|c|c|}
\hline \multicolumn{10}{|c|}{ Table 2: Growing economy } \\
\hline$v$ & $\tilde{\tau}$ & $\tilde{b}$ & $\tilde{z}$ & $\tilde{\psi}$ & $\tilde{\phi}$ & $\tilde{x}$ & $\widetilde{\Omega}$ & $\frac{\tilde{c}}{\tilde{N}}$ & $\gamma$ \\
& & & & & & & & & \\
\hline 0.206 & 0.54 & 0.60 & 0.057 & 16.7 & 41.3 & 0.42 & 2.29 & 0.0241 & 0 \\
\hline 0.21 & 0.538 & 0.603 & 0.057 & 16.69 & 41.5 & 0.42 & 2.22 & 0.0242 & 0.00005 \\
\hline 0.23 & 0.531 & 0.611 & 0.0577 & 16.69 & 43.03 & 0.40 & 1.77 & 0.023 & 0.0003 \\
\hline 0.25 & 0.52 & 0.62 & 0.058 & 16.67 & 44.4 & 0.38 & 1.38 & 0.0225 & 0.0004 \\
\hline 0.27 & 0.518 & 0.626 & 0.059 & 16.66 & 45.82 & 0.37 & 1.01 & 0.022 & 0.0009 \\
\hline 0.29 & 0.512 & 0.633 & 0.0592 & 16.64 & 47.17 & 0.357 & 0.68 & 0.021 & 0.0011 \\
\hline 0.31 & 0.507 & 0.64 & 0.06 & 16.62 & 47.8 & 0.35 & 0.53 & 0.0209 & 0.0014 \\
\hline 0.33 & 0.501 & 0.647 & 0.061 & 16.59 & 49.81 & 0.33 & 0.09 & 0.02 & 0.0016 \\
\hline
\end{tabular}

Notes: $\alpha=0.35, A=1, \delta=0.015, \rho=0.02, s=0.5$

As expected, for $v=0.206$, we go back to the non-growing solution in Table 1. For values of $0.206<v \leq 0.33$, the balanced growth rate $(\gamma)$ becomes positive, and this growth effect is monotonically increasing in $v$. Also, the higher is $v$, the lower is the tax rate $(\tau)$ and the higher is the share allocated to infrastructure vis-à-vis cleanup (b). Combing results, it follows that the more citizens care about the environment (the higher is $v$ ), the more growth-enhancing policies the government finds it optimal to choose. Intuitively, when citizens care about the environment, this requires extra tax revenues for cleanup policy and can be only achieved by large tax bases and high growth. Ramsey-type policymakers realize this and choose their policy instruments ( $\tau$ and $b$ ) accordingly. As a result, the higher is eventually the common rate $(\gamma)$ at which consumption, capital and renewable natural resources can grow.

\footnotetext{
${ }^{25}$ For $v<0.206$, the growth rate becomes negative which is not a well-defined solution because it implies that the economy shrinks in the long run. Also, for $v>0.33$, the value of $\Omega \equiv \lambda_{c} c$ becomes negative which again is not a well-defined solution with $\lambda_{c}, c>0$.

${ }^{26}$ Equation (16g) is a third-order polynomial in $\tilde{\tau}$. However, only one of the three roots is real and thus reported here. The transversality condition (11i) is also satisfied.
} 
In addition, the higher is $v$, the lower $\tilde{x} \equiv \frac{\tilde{k}}{\tilde{N}}$ gets. That is, the environment improves relative to physical capital. On the other hand, the effect of $v$ on $\frac{\tilde{C}}{\tilde{N}}$ follows an inverted-U pattern. That is, for relatively low values of $v$, consumption rises relative to environmental quality; but after a critical level, as the weight given to environmental quality rises, the opposite happens. We believe these are sensible comparative static results.

\subsection{Transitional dynamics}

We again focus on local stability around the long run. Since equations (12f) and (12g) are atemporal, linearizing (12a)-(12e) around (16a)-(16g) implies that the local dynamics are approximated by the linear system:

$$
\left[\begin{array}{c}
\dot{z} \\
\dot{\psi} \\
\dot{\phi} \\
\dot{x} \\
\dot{\boldsymbol{Q}}
\end{array}\right]=\left[\begin{array}{ccccc}
J_{z z} & J_{\psi z} & J_{\phi z} & J_{x z} & J_{\Omega z} \\
J_{z \psi} & J_{\psi \psi} & J_{\phi \psi} & J_{x \psi} & J_{\Omega \psi} \\
J_{z \phi} & J_{\psi \phi} & J_{\phi \phi} & J_{x \phi} & J_{\Omega \phi} \\
J_{z x} & J_{\psi x} & J_{\phi x} & J_{x x} & J_{\Omega x} \\
J_{z \Omega} & J_{\psi \Omega} & J_{\phi \alpha 2} & J_{x \Omega} & J_{\Omega \Omega}
\end{array}\right]\left[\begin{array}{c}
z \\
\psi \\
\phi \\
x \\
\Omega
\end{array}\right]
$$

where the new elements of the Jacobian evaluated at the log-run are shown in Appendix G. Working as in subsection 4.2 above, we show:

PROPOSITION 4: Under the conditions in Proposition 3, a long-run general equilibrium of a growing economy is saddle-path stable.

Proof: See Appendix H.

\section{CONCLUSIONS AND EXTENSIONS}

We studied second-best optimal economic policy in a general equilibrium model of endogenous growth augmented with renewable natural resources. Economic policy took the form of public infrastructure services and abatement activities financed by distorting taxes. 
Since the main results are written in the Introduction, here we only discuss possible extensions. First, it would be interesting to study a richer menu of environmental policy instruments. Here, by following common practice, we focused on taxes on polluting activities, and in turn cleanup policy financed by the collected tax revenues. But environmental management also involves the use of policy tools like controls of many sorts, property rights laws, nationalization, etc. For instance, a big policy question today - see e.g. the Kyoto protocol - seems to be the debate on pollution taxes (i.e. price-based policies) versus pollution limits (i.e. quantity-based policies). Second, it is widely believed that the policy focus should shift to cleaner technologies. In terms of modeling, adding such technologies would not change our main results (in our model, cleanup technology and pollution taxes are expected to be substitutes along the optimal policy path). The problem is how to design policies that allow market forces to play a role in encouraging private investment and innovation in such technologies. We leave these extensions for future research. 


\section{APPENDICES}

\section{Appendix A: Study of equations (9a)-(9c)}

(i) When $\frac{\dot{C}}{c}=\frac{\dot{k}}{k}=\frac{\dot{N}}{N}=\gamma>0$, equations (9a) and (9b) give:

$\frac{c}{k}=(1-\alpha)(1-\tau) A^{\frac{1}{\alpha}}(b \tau)^{\frac{1-\alpha}{\alpha}}+\rho$

while equations (9a) and (9c) give:

$$
\frac{N}{k}=\frac{[s-(1-b) \tau] A^{\frac{1}{\alpha}}(b \tau)^{\frac{1-\alpha}{\alpha}}}{\rho+\delta-\alpha(1-\tau) A^{\frac{1}{\alpha}}(b \tau)^{\frac{1-\alpha}{\alpha}}}
$$

so that (A.1) and (A.2) give:

$$
\frac{N}{C}=\frac{[s-(1-b) \tau] A^{\frac{1}{\alpha}}(b \tau)^{\frac{1-\alpha}{\alpha}}}{\left[\rho+\delta-\alpha(1-\tau) A^{\frac{1}{\alpha}}(b \tau)^{\frac{1-\alpha}{\alpha}}\right]\left[(1-\alpha)(1-\tau) A^{\frac{1}{\alpha}}(b \tau)^{\frac{1-\alpha}{\alpha}}+\rho\right]}
$$

(ii) When $\frac{\dot{c}}{c}=\frac{\dot{k}}{k}=\frac{\dot{N}}{N}=0$, (9a) requires:

$\alpha(1-\tau) A^{\frac{1}{\alpha}}(b \tau)^{\frac{1-\alpha}{\alpha}}-\rho=0$

and in turn (9b) and (9c) imply respectively:

$\frac{c}{k}=(1-\tau) A^{\frac{1}{\alpha}}(b \tau)^{\frac{1}{\alpha}}$

$\frac{N}{k}=\frac{[s-(1-b) \tau] A^{\frac{1}{\alpha}}(b \tau)^{\frac{1-\alpha}{\alpha}}}{\delta}$

so that (A.5) and (A.6) give:

$$
\frac{N}{C}=\frac{[s-(1-b) \tau]}{\delta(1-\tau)}
$$

(iii) When $\frac{\dot{C}}{c}=\frac{\dot{k}}{k}=\gamma>0$ and $\frac{\dot{N}}{N}=0$, (9a) and (9b) give:

$\frac{c}{k}=(1-\alpha)(1-\tau) A^{\frac{1}{\alpha}}(b \tau)^{\frac{1-\alpha}{\alpha}}+\rho$ 
and (9a) and (9c) give:

$$
\frac{N}{k}=\frac{[s-(1-b) \tau] A^{\frac{1}{\alpha}}(b \tau)^{\frac{1-\alpha}{\alpha}}}{\delta}
$$

so that (A.8) and (A.9) imply:

$$
\frac{N}{C}=\frac{[s-(1-b) \tau] A^{\frac{1}{\alpha}}(b \tau)^{\frac{1-\alpha}{\alpha}}}{\delta\left[(1-\alpha)(1-\tau) A^{\frac{1}{\alpha}}(b \tau)^{\frac{1-\alpha}{\alpha}}+\rho\right]}
$$

It is then easy to check that the comparative statics, as written in the text, follow (where $[s-(1-b) \tau]$ is assumed to be positive to have well-defined solutions).

\section{Appendix B: From equations (11a)-(11h) to equations (12a)-(12g)}

Equations (11a)-(11h) in the text constitute an eight-equation dynamic system in $\tau, b, \mathrm{c}, \lambda_{c}, k, \lambda_{k}, N, \lambda_{n}$. By dividing both sides of (11a) and (11b), we get (12f) in the text. Next, if we define $z \equiv \frac{c}{k}, \psi \equiv \lambda_{k} k, \phi \equiv \lambda_{n} N, x \equiv \frac{k}{N}$ and $\Omega \equiv \lambda_{c} c$, equations (11a), (11c), (11d), (11e), (11f), (11g) and (11h) give (12a), (12b), (12c), (12d), (12e) and $(12 \mathrm{~g})$ in the text.

\section{Appendix C: Proof of Proposition 1}

Equation (13c) implies that for $\tilde{\phi}>0$, we need:

$\rho>\delta$

Since the economy's growth rate is zero, $\alpha(1-\tilde{\tau}) A^{\frac{1}{\alpha}}(\tilde{b} \tilde{\tau})^{\frac{1-\alpha}{\alpha}}-\rho=0$, where $0<\alpha<1$, it follows:

$(1-\tilde{\tau}) A^{\frac{1}{\alpha}}(\tilde{b} \tilde{\tau})^{\frac{1-\alpha}{\alpha}}-\rho>0$

Hence, if (C.1) holds, (13b) implies $\tilde{\psi}>0$.

Equation (13d) implies that for $\tilde{x}>0$, we need:

$\tilde{\tau}<1-\alpha+\alpha s$

Equation (13e) implies that for $\tilde{\Omega}>0$, we need:

$\rho>\delta+\frac{v \delta}{1-\alpha}$ 
Equation (13f) implies that for $0<\tilde{b}<1$, we need:

$\tilde{\tau}>1-\alpha-(1-\alpha) s$

Combining (C.1) and (C.3), and if (C.1) holds, (C.3) is satisfied as well. Combining (C.2) and (C.4), we get:

$1-\alpha-(1-\alpha) s<\tilde{\tau}<1-\alpha+\alpha s$

Combining (C.5) and (13g) in the text, we get:

$\alpha^{2}(1-s) A^{\frac{1}{\alpha}}((1-\alpha)(1-s))^{\frac{1-\alpha}{\alpha}}<\rho<\alpha(s+\alpha(1-s)) A^{\frac{1}{\alpha}}((1-\alpha)(1-s))^{\frac{1-\alpha}{\alpha}}$

Finally, (12g) implies that the following condition must hold:

$(\rho-\delta)\left(\rho-\alpha^{2}(1-s) A^{\frac{1}{\alpha}}((1-\alpha)(1-s))^{\frac{1-\alpha}{\alpha}}\right)=v \delta \rho$

Conditions (C.1), (C.6) and (C.7) are respectively (14a), (14b) and (14c) in the text.

\section{Appendix D: The Jacobian in equation (15)}

The elements of the Jacobian matrix evaluated at the steady state are:

$$
\begin{aligned}
& J_{z z}=\tilde{z}>0, J_{\psi z}=0, J_{\phi z}=0, J_{x z}=0, J_{\Omega z}=0, \quad J_{z \psi}=-\tilde{\psi}<0, \quad J_{\psi \psi}=\rho-\tilde{z}<0,
\end{aligned}
$$

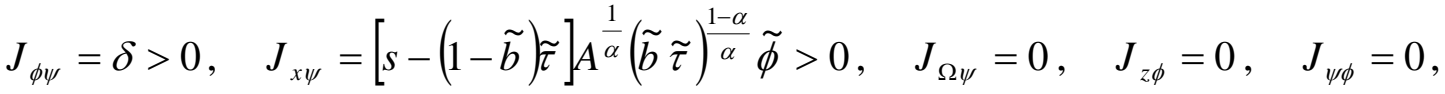

$$
\begin{aligned}
& J_{\phi \phi}=\rho-\delta>0, \quad J_{x \phi}=-[s-(1-\tilde{b}) \tilde{\tau}] A^{\frac{1}{\alpha}}(\tilde{b} \tilde{\tau})^{\frac{1-\alpha}{\alpha}} \tilde{\phi}<0, \quad J_{\Omega \phi}=0, \quad J_{z x}=-\tilde{x}<0, \\
& J_{\psi x}=0, \quad J_{\phi x}=0, \quad J_{x x}=\delta>0, \quad J_{\Omega x}=0, \quad J_{z \Omega}=\tilde{\psi}>0, \quad J_{\psi \Omega}=\tilde{z}>0, \quad J_{\phi \Omega}=0, \\
& J_{\chi \Omega}=0, J_{\Omega \Omega}=\rho>0 .
\end{aligned}
$$

\section{Appendix E: Proof of Proposition 2}

The characteristic polynomial of the Jacobian in (15) evaluated at the steady state is:

$\left(\varepsilon-J_{z z}\right)\left(\varepsilon-J_{\psi \psi}\right)\left(\varepsilon-J_{\phi \phi}\right)\left(\varepsilon-J_{x x}\right)\left(\varepsilon-J_{\Omega \Omega}\right)=0$

where $\varepsilon$ is an eigenvalue and where $J_{z z}, J_{\psi \psi}, J_{\phi \phi}, J_{x x}, J_{\Omega \Omega}$ are given in Appendix D above. Then, equation (E.1) implies four positive and one negative roots. Since four variables are jump ( $z, \psi, \phi$ and $\Omega$ ) and one variable is predetermined $(x)$, this gives local determinacy (i.e. saddle-path stability). 


\section{Appendix F: Proof of Proposition 3}

Equation (16c) implies that for $\tilde{\phi}>0$, we need:

$\alpha(1-\tilde{\tau}) A^{\frac{1}{\alpha}}(\tilde{b} \tilde{\tau})^{\frac{1-\alpha}{\alpha}}-\delta>0$

Given (F.1), equation (16b) implies that for $\tilde{\psi}>0$, we need:

$\rho+\delta-\alpha(1-\tilde{\tau}) A^{\frac{1}{\alpha}}(\tilde{b} \tilde{\tau})^{\frac{1-\alpha}{\alpha}}>0$

Equation (16d) implies that for $\tilde{x}>0$, we need:

$\tilde{\tau}<1-\alpha+\alpha s$

Equation (16e) implies that for $\tilde{\Omega}>0$, we need:

$$
\begin{aligned}
& (1-\alpha)(1-\tilde{\tau}) A^{\frac{1}{\alpha}}((1-\alpha)(1-s))^{1-\alpha} \alpha\left(\alpha A^{\frac{1}{\alpha}}((1-\alpha)(1-s))^{\frac{1-\alpha}{\alpha}}-\delta\right)- \\
& v\left(\rho+\delta-\alpha(1-\tilde{\tau}) A^{\frac{1}{\alpha}}((1-\alpha)(1-s))^{\frac{1-\alpha}{\alpha}}\right)\left((1-\alpha)(1-\tilde{\tau}) A^{\frac{1}{\alpha}}((1-\alpha)(1-s))^{\frac{1-\alpha}{\alpha}}+\rho\right)>0
\end{aligned}
$$

Equation (16f) implies that for $0<\tilde{b}<1$, we need:

$\tilde{\tau}>1-\alpha-(1-\alpha) s$

For the growth rate to be positive we need:

$\alpha(1-\tilde{\tau}) A^{\frac{1}{\alpha}}(\tilde{b} \tilde{\tau})^{\frac{1-\alpha}{\alpha}}-\rho>0$

For the transversality condition in (11i) to hold, we need:

$\alpha(1-\tilde{\tau}) A^{\frac{1}{\alpha}}(\tilde{b} \tilde{\tau})^{\frac{1-\alpha}{\alpha}}-\rho<\rho-\delta$

Equation (F.7), given that (F.6) holds, implies that:

$\rho>\delta$

If (F.8) holds and also the growth rate is positive (see condition (F.6)), then (F.1) is satisfied as well. Also, if:

$\rho<2 \delta$

then, if (F.7) holds, (F.2) is always satisfied.

Combining, (F.6) and (F.7), we get (17a) in the text. Combining (F.8) and (F.9) we obtain (17b) in the text. Finally, (F.4) is (17c) in the text.

Therefore, if (17a), (17b) and (17c) in the text hold, the tax rate(s), $\tilde{\tau}$, and the

allocation(s) of tax revenues between infrastructure and cleanup, $\tilde{b}$, as well as the 
associated SBGP(s), will be well defined (given existence of a solution). In particular, by combining (F.3) and (F.5), we get that $\tilde{\tau}$ must lie within the region:

$1-\alpha-s(1-\alpha)<\tilde{\tau}<1-\alpha+\alpha s$

and $\tilde{b}$ must lie within the region:

$$
1-\frac{s}{1-\alpha+\alpha s}<\tilde{b}<1
$$

We now check existence of such an equilibrium. To do so, we study (16g) in the text.

Let define as $L(\tilde{\tau})$ and $R(\tilde{\tau})$ the left- and the right-hand side of (16g) respectively.

Then, it is easy to show that $L(0)>0, L(1)=0, R(0)>0, R(1)>0$. Also, $\frac{\partial L(\tilde{\tau})}{\partial \tilde{\tau}}<0$.

Hence, by combining all these, a sufficient condition for existence is $L(0)>R(0)$, which is $(17 \mathrm{~d})$ in the text.

\section{Appendix G: The Jacobian in equation (18)}

The elements of the Jacobian matrix evaluated at the steady state are:

$$
\begin{aligned}
& J_{z z}=\tilde{z}>0, J_{\psi z}=0, J_{\phi z}=0, J_{x z}=0, J_{\Omega z}=0, \quad J_{z \psi}=-\tilde{\psi}<0, \quad J_{\psi \psi}=\rho-\tilde{z}<0, \\
& J_{\phi \psi}=\rho+\delta-\alpha(1-\tilde{\tau}) A^{\frac{1}{\alpha}}(\tilde{b} \tilde{\tau})^{\frac{1-\alpha}{\alpha}}>0, J_{x \psi}=[s-(1-\tilde{b}) \tilde{\tau}] A^{\frac{1}{\alpha}}(\tilde{b} \tilde{\tau})^{\frac{1-\alpha}{\alpha}} \tilde{\phi}>0, J_{\Omega \psi}=0, \\
& J_{z \phi}=0, \quad J_{\psi \phi}=0, \quad J_{\phi \phi}=\alpha(1-\tilde{\tau}) A^{\frac{1}{\alpha}(\tilde{b} \tilde{\tau})^{1-\alpha}}-\delta>0, \quad J_{x \phi}=-[s-(1-\tilde{b}) \tilde{\tau}] A^{\frac{1}{\alpha}}(\tilde{b} \tilde{\tau})^{\frac{1-\alpha}{\alpha}} \tilde{\phi}<0, \\
& J_{\Omega \phi}=0, \quad J_{z x}=-\tilde{x}<0, \quad J_{\psi x}=0, \quad J_{\phi x}=0, \quad J_{x x}=\rho+\delta-\alpha(1-\tilde{\tau}) A^{\frac{1}{\alpha}}(\tilde{b} \tilde{\tau})^{\frac{1-\alpha}{\alpha}}>0, \\
& J_{\Omega x}=0, J_{z \Omega}=\tilde{\psi}>0, J_{\psi \Omega}=\tilde{z}>0, J_{\phi \Omega}=0, J_{x \Omega}=0, J_{\Omega \Omega}=\rho>0 .
\end{aligned}
$$

\section{Appendix H: Proof of Proposition 4}

The characteristic polynomial of the Jacobian in (18) evaluated at the steady state is: $\left(\varepsilon-J_{z z}\right)\left(\varepsilon-J_{\psi \psi}\right)\left(\varepsilon-J_{\phi \phi}\right)\left(\varepsilon-J_{x x}\right)\left(\varepsilon-J_{\Omega \Omega}\right)=0$

where $\varepsilon$ is an eigenvalue and where $J_{z z}, J_{\psi \psi}, J_{\phi \phi}, J_{x x}, J_{\Omega \Omega}$ are given in Appendix G. Then, equation (H.1) implies four positive and one negative roots. Since four variables are jump ( $z, \psi, \phi$ and $\Omega$ ) and one variable is predetermined $(x)$, this gives local determinacy (i.e. saddle-path stability). 


\section{REFERENCES}

Aghion P. and P. Howitt (1998): Endogenous Growth Theory. MIT Press. Cambridge, Mass.

Barro R. (1990): Government spending in a simple model of endogenous growth, Journal of Political Economy, 98, S103-S125.

Benhabib J. and R. Farmer (1999): Indeterminacy and sunspots in macroeconomics, in Handbook of Macroeconomics, volume I, edited by J. Taylor and M. Woodford. North-Holland. Amsterdam.

Bovenberg A. L. and S. Smulders (1995): Environmental quality and pollutionaugmenting technological change in a two-sector endogenous growth model, Journal of Public Economics, 57, 369-391.

Bovenberg A. L. and S. Smulders (1996): Transitional impacts of environmental policy in an endogenous growth model, International Economic Review, 37, 861-893.

Grossman G. and A. Krueger (1995): Economic growth and the environment, Quarterly Journal of Economics, CX, 2, 353-377.

John A. and R. Pecchenino (1994): An overlapping generations model of growth and the environment, Economic Journal, 104, 1393-1410.

Jones L. and R. Manuelli (2001): Endogenous policy choice: the case of pollution and growth, Review of Economic Dynamics, 4, 369-405.

Kamien M. and N. Schwartz (1991): Dynamic Optimization. $2^{\text {nd }}$ edition. Elsevier. Amsterdam.

Kolstad C. and J. Krautkraemer (1993): Natural resource use and the environment, in the Handbook of Natural Resource and Energy Economics, volume III, edited by A. Kneese and J. Sweeney. North-Holland, Amsterdam.

Ligthart J. and F. van der Ploeg (1994): Pollution, the cost of public funds and endogenous growth, Economics Letters, 46, 339-349.

Mulligan C. B. and X. Sala-i-Martin (1993): Transitional dynamics in two-sector models of endogenous growth, Quarterly Journal of Economics, 108 (3), 739-773.

Park H. and A. Philippopoulos (2004): Indeterminacy and fiscal policies in a growing economy, Journal of Economic Dynamics and Control, 28 (4), 645-660.

Perman R., Y. Ma, J. McGilvray and M. S. Common (2003): Natural Resources and Environmental Economics. $3^{\text {rd }}$ edition. Pearson Education. Harlow. 
Philippopoulos A. and G. Economides (2003): Are Nash tax rates too low or too high? The role of endogenous growth in models with public goods, Review of Economic Dynamics, 6, 37-53.

Ploeg S. and C. Withagen (1991): Pollution control and the Ramsey problem, Environmental and Resource Economics, 1, 215-236.

Tahvonen O. and J. Kuuluvainen (1993): Economic growth, pollution and renewable resources, Journal of Environmental Economics and Management, 24, 101-118. 


\title{
CESifo Working Paper Series
}

\author{
(for full list see www.cesifo.de)
}

1370 András Simonovits, Designing Benefit Rules for Flexible Retirement with or without Redistribution, December 2004

1371 Antonis Adam, Macroeconomic Effects of Social Security Privatization in a Small Unionized Economy, December 2004

1372 Andrew Hughes Hallett, Post-Thatcher Fiscal Strategies in the U.K.: An Interpretation, December 2004

1373 Hendrik Hakenes and Martin Peitz, Umbrella Branding and the Provision of Quality, December 2004

1374 Sascha O. Becker, Karolina Ekholm, Robert Jäckle and Marc-Andreas Mündler, Location Choice and Employment Decisions: A Comparison of German and Swedish Multinationals, January 2005

1375 Christian Gollier, The Consumption-Based Determinants of the Term Structure of Discount Rates, January 2005

1376 Giovanni Di Bartolomeo, Jacob Engwerda, Joseph Plasmans, Bas van Aarle and Tomasz Michalak, Macroeconomic Stabilization Policies in the EMU: Spillovers, Asymmetries, and Institutions, January 2005

1377 Luis H. R. Alvarez and Erkki Koskela, Progressive Taxation and Irreversible Investment under Uncertainty, January 2005

1378 Theodore C. Bergstrom and John L. Hartman, Demographics and the Political Sustainability of Pay-as-you-go Social Security, January 2005

1379 Bruno S. Frey and Margit Osterloh, Yes, Managers Should Be Paid Like Bureaucrats, January 2005

1380 Oliver Hülsewig, Eric Mayer and Timo Wollmershäuser, Bank Loan Supply and Monetary Policy Transmission in Germany: An Assessment Based on Matching Impulse Responses, January 2005

1381 Alessandro Balestrino and Umberto Galmarini, On the Redistributive Properties of Presumptive Taxation, January 2005

1382 Christian Gollier, Optimal Illusions and Decisions under Risk, January 2005

1383 Daniel Mejía and Marc St-Pierre, Unequal Opportunities and Human Capital Formation, January 2005 
1384 Luis H. R. Alvarez and Erkki Koskela, Optimal Harvesting under Resource Stock and Price Uncertainty, January 2005

1385 Ruslan Lukach, Peter M. Kort and Joseph Plasmans, Optimal R\&D Investment Strategies with Quantity Competition under the Threat of Superior Entry, January 2005

1386 Alfred Greiner, Uwe Koeller and Willi Semmler, Testing Sustainability of German Fiscal Policy. Evidence for the Period 1960 - 2003, January 2005

1387 Gebhard Kirchgässner and Tobias Schulz, Expected Closeness or Mobilisation: Why Do Voters Go to the Polls? Empirical Results for Switzerland, 1981 - 1999, January 2005

1388 Emanuele Bacchiocchi and Alessandro Missale, Managing Debt Stability, January 2005

1389 Assar Lindbeck and Dirk Niepelt, Improving the SGP: Taxes and Delegation rather than Fines, January 2005

1390 James J. Heckman and Dimitriy V. Masterov, Skill Policies for Scotland, January 2005

1391 Emma Galli \& Fabio Padovano, Sustainability and Determinants of Italian Public Deficits before and after Maastricht, January 2005

1392 Angel de la Fuente and Juan Francisco Jimeno, The Private and Fiscal Returns to Schooling and the Effect of Public Policies on Private Incentives to Invest in Education: A General Framework and Some Results for the EU, January 2005

1393 Juan C. Conesa and Carlos Garriga, Optimal Response to a Demographic Shock, January 2005

1394 Christian Gollier, Optimal Portfolio Management for Individual Pension Plans, February 2005

1395 Ruslan Lukach, Joseph Plasmans and Peter M. Kort, Innovation Strategies in a Competitive Dynamic Setting, February 2005

1396 Gebhard Kirchgässner, (Why) Are Economists Different?, February 2005

1397 Marko Köthenbürger, Panu Poutvaara and Paola Profeta, Why are More Redistributive Social Security Systems Smaller? A Median Voter Approach, February 2005

1398 Gabrielle Demange, Free Choice of Unfunded Systems: A First Assessment, February 2005

1399 Carlos Fonseca Marinheiro, Sustainability of Portuguese Fiscal Policy in Historical Perspective, February 2005

1400 Roel M. W. J. Beetsma and Koen Vermeylen, The Effect of Monetary Unification on Public Debt and its Real Return, February 2005 
1401 Frank Asche, Petter Osmundsen and Maria Sandsmark, Is It All Oil?, February 2005

1402 Giacomo Corneo, Media Capture in a Democracy: The Role of Wealth Concentration, February 2005

1403 A. Lans Bovenberg and Thijs Knaap, Ageing, Funded Pensions and the Dutch Economy, February 2005

1404 Thiess Büttner, The Incentive Effect of Fiscal Equalization Transfers on Tax Policy, February 2005

1405 Luisa Fuster, Ayşe İmrohoroğlu and Selahattin İmrohoroğlu, Personal Security Accounts and Mandatory Annuitization in a Dynastic Framework, February 2005

1406 Peter Claeys, Policy Mix and Debt Sustainability: Evidence from Fiscal Policy Rules, February 2005

1407 James M. Malcomson, Supplier Discretion over Provision: Theory and an Application to Medical Care, February 2005

1408 Thorvaldur Gylfason, Interview with Assar Lindbeck, February 2005

1409 Christian Gollier, Some Aspects of the Economics of Catastrophe Risk Insurance, February 2005

1410 Gebhard Kirchgässner, The Weak Rationality Principle in Economics, February 2005

1411 Carlos José Fonseca Marinheiro, Has the Stability and Growth Pact Stabilised? Evidence from a Panel of 12 European Countries and Some Implications for the Reform of the Pact, February 2005

1412 Petter Osmundsen, Frank Asche, Bård Misund and Klaus Mohn, Valuation of International Oil Companies -The RoACE Era, February 2005

1413 Gil S. Epstein and Shmuel Nitzan, Lobbying and Compromise, February 2005

1414 Marcel F. M. Canoy, Jan C. van Ours and Frederick van der Ploeg, The Economics of Books, February 2005

1415 Eric A. Hanushek and Ludger Wößmann, Does Educational Tracking Affect Performance and Inequality? Differences-in-Differences Evidence across Countries, February 2005

1416 George Kapetanios and M. Hashem Pesaran, Alternative Approaches to Estimation and Inference in Large Multifactor Panels: Small Sample Results with an Application to Modelling of Asset Returns, February 2005

1417 Samuel Mühlemann, Jürg Schweri, Rainer Winkelmann and Stefan C. Wolter, A Structural Model of Demand for Apprentices. February 2005 
1418 Giorgio Brunello and Lorenzo Rocco, Educational Standards in Private and Public Schools, February 2005

1419 Alex Bryson, Lorenzo Cappellari and Claudio Lucifora, Why so Unhappy? The Effects of Unionisation on Job Satisfaction, March 2005

1420 Annalisa Luporini, Relative Performance Evaluation in a Multi-Plant Firm, March 2005

1421 Giorgio Bellettini and Carlotta Berti Ceroni, When the Union Hurts the Workers: A Positive Analysis of Immigration Policy, March 2005

1422 Pieter Gautier, Michael Svarer and Coen Teulings, Marriage and the City, March 2005

1423 Ingrid Ott and Stephen J. Turnovsky, Excludable and Non-Excludable Public Inputs: Consequences for Economic Growth, March 2005

1424 Frederick van der Ploeg, Back to Keynes?, March 2005

1425 Stephane Dees, Filippo di Mauro, M. Hashem Pesaran and L. Vanessa Smith, Exploring the International Linkages of the Euro Area: a Global VAR Analysis, March 2005

1426 Hans Pitlik, Friedrich Schneider and Harald Strotmann, Legislative Malapportionment and the Politicization of Germany's Intergovernmental Transfer System, March 2005

1427 Konstantinos Angelopoulos and Apostolis Philippopoulos, The Role of Government in Anti-Social Redistributive Activities, March 2005

1428 Ansgar Belke and Daniel Gros, Asymmetries in the Trans-Atlantic Monetary Policy Relationship: Does the ECB follow the Fed?, March 2005

1429 Sören Blomquist and Luca Micheletto, Optimal Redistributive Taxation when Government's and Agents' Preferences Differ, March 2005

1430 Olof Åslund and Peter Fredriksson, Ethnic Enclaves and Welfare Cultures - QuasiExperimental Evidence, March 2005

1431 Paul De Grauwe, Roberto Dieci and Marianna Grimaldi, Fundamental and NonFundamental Equilibria in the Foreign Exchange Market. A Behavioural Finance Framework, March 2005

1432 Peter Egger, Stefan Gruber, Mario Larch and Michael Pfaffermayr, Knowledge-Capital Meets New Economic Geography, March 2005

1433 George Economides and Apostolis Philippopoulos, Should Green Governments Give Priority to Environmental Policies over Growth-Enhancing Policies?, March 2005 